RAEIC, Revista de la Asociación Española de Investigación

de la Comunicación

vol. 6, núm. 12 (2019), 123-146

ISSN 2341-2690

Recibido el 6 de marzo de 2019

DoI: https://doi.org/10.24137/raeic.6.12.12

Aceptado el 2 de mayo de 2019

\title{
Reformulando el concepto de actividad de la audiencia en la era digital
}

Rethinking the concept of audience activity in the digital age

\author{
Rivas-de-Roca, Rubén \\ Universidad de Sevilla \\ rrivasderoca@us.es
}

\section{Forma de citar este artículo:}

Rivas-de-Roca, R. (2019). Reformulando el concepto de actividad de la audiencia en la era digital. RAEIC, Revista de la Asociación Española de Investigación de la Comunicación, vol. 6, núm. 12, 123-146.

\section{Resumen:}

La expansión de las tecnologías informacionales supone una oportunidad para el desarrollo de una participación activa de las audiencias. La idea de actividad formulada por el modelo canónico de codificación/decodificación puede adaptarse a los nuevos tipos de interactividad generados en el panorama digital. En este sentido, la propuesta de Hall goza de vigencia explicativa, pero se enfrenta a desafíos metodológicos que ponen en cuestión el estudio de audiencias en la era digital. Este artículo profundiza sobre cómo se manifiesta en la actualidad el concepto de actividad de la audiencia, poniendo el foco en la dimensión empírica de este enfoque, relevante en una sociedad actual que experimenta procesos mediados de forma continua. Para ello, se efectúa una revisión crítica sobre la operatividad del modelo codificación/decodificación, así como 
acerca de las implicaciones de una audiencia activa para los estudios de la desviación, especialmente en el contexto digital. Como conclusión se puede apuntar que la interactividad de los cibermedios se cruza con las fases de la recepción definidas por Hall -dominante, negociada y opuesta-, permitiendo el descubrimiento de implicaciones políticas en los medios digitales. Esta guía epistemológica es de gran utilidad para productos como el transmedia.

Palabras clave: audiencias, recepción, codificación/decodificación, nuevos medios.

\section{Abstract:}

Spreading of ICTs is a chance for the development of an active participation of audiences. The idea of activity formulated by the canonical coding/decoding model can be adapted to the new types of interactivity generated in the digital world. In this sense, Hall's proposal has explanatory validity, but it faces methodological challenges that question audience studies in the digital age. This paper tries to deepen on how the concept of activity of the audience is working nowadays, focusing on the empirical dimension of this approach. That is relevant in a current society that experiences continuously mediated processes. To this end, a critical review is carried out on the operability of the coding/decoding model, as well as on the implications of an active audience for deviance studies, especially in the digital context. In conclusion, it can be noted that the interactivity of the cybermedia mixes with the steps of reception defined by Hall -dominant, negotiated and opposite-, allowing the discovery of political implications in digital media. This epistemological guide is very useful for products such as transmedia.

Keywords: audiences, reception, encoding/decoding, new media.

\section{INTRODUCCIÓN}

El crecimiento de los medios digitales ha llevado a una fragmentación de las audiencias (Webster y Ksiazek, 2012), entendidas como receptores de los productos comunicativos, 
con formas de consumo ubicuas y multiplataforma (Prado, 2017). Hasta la década de 1980 prevalecía una visión pasiva de las audiencias. De acuerdo a las teorías clásicas -caso de la aguja hipodérmica de Lasswell (1982)-, los medios "operan de acuerdo a una lógica de causa-efecto, en la que la audiencia es una mera víctima pasiva de manipulación" (Buckingham, 2013, p. 56). A la audiencia se le añadía el término de "masa", proyectando sobre ella valores de atomización o debilidad (Adorno y Horkheimer, 1974).

La audiencia masiva fue el resultado de un proceso en el que intervinieron varias fuerzas: concentración urbana, abaratamiento de las tecnologías de distribución, altos costes de recepción individual o la emergencia de los Estados-nación (Bolin, 2014, p. 162). Frente a esta concepción pasiva, este artículo apuesta por indagar sobre la idea de audiencia activa, que implica que el sujeto dé sentido a su acción mediante sus usos, pero también a través de las dimensiones cognitivas y afectivas (Callejo Gallego, 1995). El concepto de audiencia activa, derivado de los estudios culturales británicos, ha sido considerado como radical desde un primer momento, ya que ampliaba los objetivos de las investigaciones sobre audiencia, incorporando todo tipo de aspectos que mediaban en los procesos comunicativos (Nightingale, 1999).

En el marco de las audiencias activas, resultan de interés las aportaciones del modelo encoding/decoding Hall (1980), en tanto en cuanto integran los estudios de audiencia en la crítica cultural, unificando los dos paradigmas previos de los estudios culturales. La literatura científica recoge la vigencia del modelo de encoding/decoding en el actual contexto digital, debido a que permite conocer mejor cómo ciertos tipos de interactividad son promovidos por las nuevas tecnologías (Shaw, 2017). La proliferación digital obliga a investigar de forma conjunta el consumo de varios medios (McCombs, 2012; Callejo Gallego, 2013), una realidad compleja en la que la propuesta de Stuart Hall goza de capacidad explicativa.

La investigación de audiencias en el mundo de Internet se encuentra en buena parte determinada por el nuevo paradigma de la participación, en el que "la audiencia juega 
un papel interpretativo clave en el circuito de la cultura" (Livingstone, 2013, p. 27). La idea de participación ya subyacía en el concepto de actividad de la audiencia, habiéndose desarrollado gracias a las redes digitales. Esta aproximación también se vincula con la articulación de las investigaciones de la desviación en el seno de los estudios de recepción.

Hay que tener en cuenta que la investigación sobre audiencias no supone un campo de estudio tan vibrante como en los años 80 o 90, en los que era objetivo central de los estudios culturales (Hermes, Van den Berg y Mol, 2013). El enfoque contemporáneo se dirige más a la conjunción de formas de producción, objetos mediáticos y audiencias. Sin embargo, la aparición de nuevo estilos de consumo vinculados a Internet, como el transmedia (Davis, 2013) o el Over the Top (Prado, 2017), suponen una oportunidad para profundizar sobre las implicaciones políticas de la actividad de la audiencia con esas tecnologías.

\section{LA VIGENCIA EL MODELO CODIFICACIÓN/DECODIFICACIÓN}

En 1973, el sociólogo británico Stuart Hall presentó en un artículo su modelo encoding/decoding (codificación/decodificación en español, denominación que vamos a seguir a partir de ahora). El nuevo sistema trataba de unificar los dos paradigmas de los estudios culturales: el culturalismo estructural y el estructuralismo europeo (Hall, 1980). El culturalista se orientaba hacia los ciudadanos, empleando para ello métodos etnográficos, mientras que el estructuralismo se dirigía a las condiciones sociales a través de la observación (Nightingale, 1999, p. 94).

Una de las principales aportaciones del modelo de codificación/decodificación consiste en la sugerencia de que el proceso comunicativo es una cadena estructurada, que cuenta con fases diferenciadas: producción, circulación, distribución/consumo y reproducción. Estas etapas se articulan mediante prácticas interconectadas que mantienen la especificidad de sus partes. La propuesta rompe la separación entre teoría y práctica, evidenciando que es posible analizar el poder de los medios mediante 
procesos sociales e ideológicos, y no desde la psicología o la experiencia personal como se venía haciendo hasta entonces (Nightingale, 1999, p. 50).

El beneficio de la propuesta de Hall radica en "situar las estructuras de producción de producción, texto y audiencia (recepción) dentro de un marco donde cada uno podría ser (...) analizado en relación con los demás" (Nightingale, 1999, p. 52). Esto permite comparar los códigos en el origen con los códigos en el destino del mensaje, mediante los cuales la audiencia interpreta el mensaje. Esta perspectiva conlleva que los productos mediáticos constituyen discursos con significado, codificados y decodificados según sus respectivas estructuras de significado, generados por los marcos de conocimiento, las relaciones de producción y la propia infraestructura técnica (Hall, 1980, p. 130).

El sistema de codificación/decodificación se fundamenta en la idea de que el estudio de los medios de comunicación no debe dirigirse a valorar lo que el emisor pretendía con el mensaje, ni lo que el receptor haya comprendido del mismo, sino que tiene que analizar las fuerzas que interactúan en la producción del mensaje (codificación) y en su recepción (decodificación). Este modelo se centra en el significado, por lo que ha sido identificado como guía para el estudio semiótico de los medios de comunicación (Nightingale, 1999, p. 51).

El modelo codificación/decodificación adoptó un posicionamiento con respecto al popular modelo del emisor-mensaje-receptor (Shannon y Weaver, 1949), considerado base clásica de los estudios de comunicación. Este paradigma de la comunicación se caracteriza por el envío de un mensaje codificado, que va desde el emisor al receptor. Los únicos elementos a tener en cuenta son la codificación y la posible existencia de ruido, es decir, de interferencias técnicas o semánticas que dificulten la comprensión del mensaje inicial. La principal preocupación de este enfoque se refiere a la precisión y a la efectivad (Fiske, 1982).

La propuesta de Hall (1980) identificaba una serie de problemas en el modelo emisormensaje-receptor: su carácter lineal, su preocupación excesiva por el nivel de 
intercambio de mensajes y la falta de una concepción estructurada de los distintos momentos comunicativos. No obstante, el modelo de codificación/decodificación acepta el sistema emisor-mensaje-receptor como una forma de descripción, reproduciendo su cadena. La diferencia se encuentra en que Hall no se preocupa por la efectividad, sino que considera al mensaje como único discurso con sentido.

Hall criticaba los propósitos administrativos del modelo emisor-mensaje-receptor, a la vez que aludía a la comunicación de masas como una compleja estructura de relaciones. Por ello, es mejor pensar la comunicación en tanto que estructura producida en distintos momentos -producción, distribución/consumo y reproducción- (Nightingale, 1999, p. 58), lo que subraya la necesidad de centrarse en lo social frente a lo tecnológico. Mientras que el modelo emisor-mensaje-receptor se preocupaba por la precisión o la efectividad y, por ende, acerca de la tecnología que las posibilita, la propuesta de Hall bebe de la escuela marxista, poniendo el enfoque en lo social.

El modelo codificación/decodificación emplea los términos del concepto emisormensaje-receptor para un contexto de audiencia en el que el consumismo ya no supone el concepto analítico central, sino que lo representa la clase social (Nightingale, 1999, pp. 56-57). Investigaciones como la de Callejo Gallego (1995) sobre la televisión emplean las categorías sociales como valores para el estudio de audiencias, ya que no todos los componentes de la sociedad se comportan de igual forma ante un mismo producto mediático. No debemos perder de vista que, como señalaba el profesor Fermín Bouza (2002), el vínculo entre cambio tecnológico y social es bidireccional, por lo que carece de sentido caer en el determinismo de que el cambio social viene provocado por las novedades tecnológicas. El cambio social requiere de un análisis profundo en sí mismo del que Hall, en la corriente de los Cultural Studies, hace bandera.

Este matiz en contra del determinismo tecnológico resulta pertinente en la actual sociedad, en la que en ocasiones los medios digitales son vistos como una oportunidad histórica de libertad, dado que "simplifican los procesos de producción para que todo el mundo se convierta en un productor mediático en potencia" (Bolin, 2014, p. 163). Sin 
embargo, esos cambios no son óbice para que la comunicación siga siendo un campo complejo en el que entran en juego numerosas variables sociales, y es que las clases no han desaparecido con el auge de Internet.

Por otro lado, el modelo de codificación/decodificación se centra en el mensaje porque considera que, a través de las fuerzas que interactúan en su producción (codificación) y forma de lectura (decodificación), es posible analizar el proceso de hegemonía política. Como recalca Nightingale, esta formulación solo posee utilidad "si adoptamos la visión lineal y el nivel interactivo del modelo emisor-mensaje-receptor" (1999, p. 60), que sirve como apoyo descriptivo para la propuesta de Hall. Por tanto, el sistema de este autor es comunitario, pero unidireccional en su funcionamiento.

La centralización del mensaje también se debe al hecho de que el modelo de codificación/decodificación valoraba al diálogo como algo transparente, pudiendo documentarse tanto el devenir del discurso como el poder de las instituciones. A pesar de que los mensajes deben ser interpretados individualmente, el proceso es trazable, por lo que el investigador puede explicar el mensaje como discurso significativo, buscando la procedencia de los significados en la comunidad de espectadores (Nightingale, 1999, p. 54). Para esta transformación del texto en un discurso significativo es imprescindible la existencia de una audiencia activa (ibídem, p. 152).

La decodificación es considerada un momento distintivo, puesto que, en la interacción lector-texto, se aseguraba la reproducción de la cultura dominante (Hall, 1980). Esta perspectiva se basa en la idea de que la audiencia está formada por el emisor y el receptor, que a su vez son parte de una estructura sociocultural conjunta en la cual se relacionan. Se produce así una variabilidad en la interpretación del mensaje televisivo, algo que no se da en el caso del modelo emisor-mensaje-receptor. Esta jerarquía en la producción del discurso hace que el método de codificación/decodificación pueda ser comparado con la teoría two-step-flow (Katz y Lazarsfeld, 1955), que establece que la comunicación de masas funciona como un flujo en dos tiempos entre líderes de opinión y el público en general. 


\section{IMPLICACIONES DE UNA AUDIENCIA ACTIVA PARA LOS ESTUDIOS DE LA DESVIACIÓN}

Los estudios culturales de audiencia se caracterizan por tres grandes paradigmas: usos y gratificaciones, investigación de los efectos y subcultura/desviación (Nightingale, 1999, p. 14). El proyecto de codificación/decodificación está unido a las investigaciones sobre subcultura y desviación (Hall y Jefferson, 1975). De acuerdo a estos autores, la relación entre cultura y subcultura consolida la dominación hegemónica de un grupo de ideas. Las prácticas subculturales son prácticas significativas, demostrando la relación del grupo con la cultura dominante (Williams, 1981).

El vínculo entre cultura y subcultura actúa como un reproductor de la dominación hegemónica, a la que se otorga un valor negativo, dado que supone el predominio único de un grupo social que impone su moral. La lógica de esta dominación hegemónica tiene mucho de inevitable en la sociedad capitalista: los medios siempre van a reforzar a la cultura dominante (Hall, 1980), en tanto en cuanto "la comunicación de masas era equiparable a las estructuras de producción económica dentro de la sociedad capitalista" (Nightingale, 1999, p. 59).

Es importante tener en cuenta el valor de las subculturas en el marco del concepto de audiencia activa desarrollado por el modelo de codificación/decodificación. La propuesta de Hall se enmarca en los estudios culturales, que consideran a las subculturas alternativas y desviadas como un objeto apropiado mediante métodos etnográficos. Bajo este enfoque, el modelo de Hall (1980) identifica tres hipotéticas formas de recepción, en las que se aprecia el vínculo con las subculturas:

- Dominante. El lector decodifica el mensaje siguiendo el código dominante, generado por el discurso hegemónico.

- Negociada. Se aplican elementos adaptativos, esto es, la combinación del discurso mayoritario con interpretaciones más ad hoc, fruto de una lógica de la negociación. 
- Opuesta. El receptor decodifica el mensaje de forma contraria al marco de referencia, a pesar de que comprende los códigos predominantes. Se trata, por tanto, de una decisión premeditada, que lleva a Hall (1980) a valorar esa reinterpretación como la gran oportunidad para que se produzca una política de significación activa por parte de la audiencia. Autores como Fiske (1987) subrayan la posibilidad de que la audiencia desarrolle soluciones frente a los códigos dominantes en la sociedad.

Los Cultural Studies británicos asumen la teoría de Williams sobre totalidad cultural, que supone percepciones antropológicas y sociológicas que consideran a la cultura como un modo de vida completo (Williams, 1981, p. 13). Este autor coindice en afirmar que las prácticas subculturales actúan como una postura de resistencia, que se manifiesta tanto en forma de negociación como de oposición frente al discurso hegemónico. Las instituciones mediáticas son, a través de sus mensajes, las grandes reproductoras de hegemonía, estableciendo diferencias entre culturas y subculturas. El poder de las instituciones es menor en modelos derivados de este culturalismo británico, como la propuesta de codificación/decodificación. La capacidad de la audiencia resulta manifiesta en la decodificación, en la cual "la audiencia puede elegir entre estar de acuerdo con este mensaje, estar en desacuerdo o elegir una vía intermedia, dependiendo de la política del mensaje y de las relaciones de clase" (Nightingale, 1999, p. 63).

En el marco de los Cultural Studies se aplica asimismo el concepto de formas de consumo, que relaciona las acciones comunicativas con el resto de prácticas cotidianas. Estas formas recogen el contexto espacio-temporal de la relación comunicativa. En palabras de Callejo Gallego, en la televisión las formas de consumo "se incrustan en las perspectivas de la audiencia como elemento activo, ya que tiende a hacer de la audiencia, como agente global que sustenta unas formas de consumo, el sujeto en relación con la televisión" (1995, p. 180). El sentido organizado de estas acciones se halla en las estrategias de consumo, un patrón generalista asentado que enlaza con la citada estructura social (Merton, 1980). 
La sociología de comunicación se ha esforzado por extraer la idea de masas del concepto audiencias, rehuyendo de argumentos simplistas y relaciones causas-efecto, algo que no ha sido muchas veces fácil debido al asentamiento de estas posiciones en la opinión pública (Buckingham, 2013). En cualquier caso, este distanciamiento del enfoque audiencia-masa no quiere decir que debamos considerar a las audiencias como únicas depositarias del poder, siendo más preciso concebir a la audiencia en plural -las audiencias-, como el conjunto heterogéneo que es (Callejo Gallego, 1995, p. 255).

La codificación/decodificación presenta distintas críticas desde la literatura. Una de ellas alude a que el proceso de lectura (decodificación), clave para entender el poder de las instituciones mediáticas, se encuentra infrateorizado en ese modelo. Siguiendo el punto de vista de la propuesta de Hall, Sless (1986) argumenta que el lector construye activamente la postura del autor, lo que a la vez le sirve para adoptar posiciones con respecto a él. Científicos sociales posteriores en la investigación sobre la dimensión activa de la audiencia, caso de Morley (1980), critican también el modelo codificación/decodificación en virtud de que reduce la comprensión del proceso de codificación a los mensajes ideológicos. La valoración de Morley es asimismo objeto de críticas académicas (Alonso Alonso, 2011), en tanto en cuanto olvida que la recepción es un proceso especialmente politizado (Ang, 1995).

La mayor contribución de Morley (1980) gira en torno a la conclusión de que un mismo objeto mediático tiene distintas significaciones según la cultura. Para este investigador, "las clases sociales instauran determinados sistemas de sentido o marcos ideológicos que se expresan en decodificaciones diferenciadas de los mensajes de los medios por diferentes sectores de la audiencia" (Alonso Alonso, 2011, p. 9). Estos tres espacios significantes son el sistema de valores dominante, el sistema de valores subordinado y el sistema de valores radical, que se pueden relacionar con las tres formas de recepción identificadas por Hall: dominante, negociada y opositora. Los medios tienen la responsabilidad de enviar contenido que se adapte a uno de estos marcos de recepción. 
A este respecto, la concepción del medio viene determinada por la posición en la estructura social, causante del conjunto de significados organizativos de su experiencia (Giddens, 1984). Existen investigaciones empíricas sobre medios de comunicación, como la de Callejo Gallego (2013) referente a jóvenes y adolescentes, que atestiguan que "tanto la edad, como el género o el nivel de estudios alcanzado, y los distintos condicionamientos sociales (...) se han mostrado ineludibles al explicar los tiempos de dedicación a los distintos medios de comunicación" (Callejo Gallego, 2013, p. 16). Esa investigación refleja asimismo que el uso plurimediático es mayor en jóvenes, no conformando los jóvenes y adolescentes -a pesar de su similitud formal- un grupo homogéneo en su relación con los medios de comunicación, lo que llama la atención sobre las imprecisiones que pueden presentar las aproximaciones apriorísticas.

La investigación sobre la recepción del modelo codificación/decodificación posee además un vínculo claro con los estudios referentes a la desviación. Como se ha recogido, las investigaciones sobre subculturas y desviación estaban muy presentes en el sistema de Hall, debido al carácter marxista y culturalista de los Cultural Studies en los que se inscribe. De hecho, las primeras investigaciones de Hall y Jefferson (1975) no se dirigían a los medios de comunicación, sino a la subcultura. Por ello, Nightingale sostiene que "el modelo de codificación/decodificación fue un desarrollo de las subculturas de la desviación, suponiendo un hito en la apropiación del estructuralismo europeo por parte del culturalismo británico" (1999, p. 56).

Las investigaciones sobre desviación sirvieron como base, como esquema epistemológico previo, para la investigación británica sobre recepción. En consecuencia, los estudios culturales orientados al ámbito de los medios de comunicación van a caracterizarse por una elevada preocupación por las cuestiones de la desviación, tales como subculturas obreras o resistencia cultural. Su objetivo último consiste en describir los constructos culturales hegemónicos que definen el proceso comunicativo de decodificación. 


\section{LA ACTIVIDAD DE LA AUDIENCIA EN EL CONTEXTO DIGITAL}

Cabe preguntarse cuál es el contexto sociocultural y tecnológico en el que procede actualmente la audiencia, algo que imbrica eminentemente con el desarrollo de la Red. Lievrouw y Livingstone (2006) han definido la infraestructura de medios digitales en términos de artefactos (tecnologías), actividades (prácticas de compromiso) y asuntos sociales (estructuras sociales, organización y gobernanza). Esto significa que la comunicación mediada se integra en diversas esferas de la sociedad, teniendo implicaciones para la apertura de oportunidades de actuación de cara al público. Aparecen nuevos géneros de participación, maneras en las que la cultura toma forma en estilos convencionales de representación (Livingstone, 2013, p. 26).

El panorama comunicativo actual viene marcado por el crecimiento de los medios digitales, causa de una fragmentación de la audiencia a veces considerada como prueba de la polarización social (Webster y Ksiazek, 2012). A priori existe una mayor oferta, unida a posibilidades de consumo bajo demanda, si bien buena parte de la producción se encuentra controlada por grandes gigantes tecnológicos, como Google, Facebook o Netflix. Algunos académicos valoran esta pluralidad como señal de un mercado mediático robusto (Anderson, 2006), mientras que otros alertan del peligro para una cultura común que supone la emergencia de multinacionales mediáticas (Sunstein, 2007).

En cualquier caso, Webster y Ksiazek (2012) indican que resulta probable que las audiencias se mantengan concentradas en el mercado de los medios digitales. Esto se debe al diferencial de calidad de los productos, la deseabilidad social de las selecciones mediáticas y las medidas de los medios para informar de las elecciones de los usuarios (Webster y Ksiazek, 2012, p. 51). Por ello, es de utilidad realizar aproximaciones analíticas en red con respecto a la fragmentación, en las que aparecerán nodos y duplicidades que determinarán si el receptor actúa más como consumidor o como ciudadano. 
Desde un punto de vista comercial, atraer a la audiencia continúa siendo un prerrequisito para que los productos informativos alcancen sus objetivos económicos, sociales o políticos (Lanham, 2006), tal y como lo era en los medios de comunicación de masas tradicionales. Los medios necesitan saber qué hacen los usuarios para poder desarrollar objetos comunicativos en consecuencia, ya que el modelo se fundamenta en vender las audiencias a los anunciantes (Bolin, 2014). Para ello se desarrollan distintos métodos, aunque la mediación de audiencias sea metodológicamente compleja (Ang, 1991).

En la actualidad, Internet y los teléfonos móviles proporcionan mucha información de los usuarios a los anunciantes, a la vez que ofrecen un enorme rango de posibilidades para dirigirse a estos miembros de la audiencia. La libertad de elección que el individuo percibe en la Red es también base del negocio digital, en el que la actividad de la audiencia se convierte en valor económico para las industrias mediáticas (Bolin, 2014, p. 161). Este modelo basado en la audiencia se intensifica gracias a las redes sociales. El conjunto del negocio digital depende de la cooperación entre redes de anunciantes, proveedores de servicios de Internet y motores de búsqueda.

Desde una perspectiva social, los debates sobre las audiencias de los medios constituyen una constante preocupación para los propios medios. Prevalecen lugares comunes en torno a las consecuencias negativas de los productos mediáticos, especialmente con respecto a los niños y adolescentes (Buckingham, 2013), lo que dificulta a los investigadores sobre este tema la divulgación de sus resultados en la esfera pública. En un contexto periodístico de relajación de los estándares profesionales motivado por las nuevas tecnologías (Gómez Mompart, Gutiérrez Lozano y Palau Sampio, 2015), los cibermedios y las televisiones dan preferencia a los estudios neurocientíficos o las teorías psicológicas para los efectos mediáticos, que generan titulares más espectaculares sobre los supuestos perjuicios de los medios. Se carece de la perspectiva sociológica, más sosegada y compleja en sus investigaciones, propia de los Cultural Studies. 
La comunicación mediada ya no es exclusivamente una comunicación masiva jerarquizada, de un emisor a muchos receptores, sino que los medios admiten ahora posibilidades de comunicación entre pares (Livingstone, 2004). En el ámbito institucional se habla de una tercera era de la comunicación política (Blumler y Kavanagh, 1999), cuya última novedad han sido las redes sociales (Bimber, 2014). Las potencialidades interactivas digitales colocan las actividades interpretativas de la gente común en el centro de la acción de los medios.

A partir de las investigaciones durante una década (2004-2014) del Consortium on Emerging Directions in Audience Research (CEDAR), un estudio de Das (2017) concluye que las principales transformaciones para los estudios de audiencia han sido cuatro: las estrategias cambiantes de la audiencia a la hora de afrontar una realidad marcada por unos medios hiperconectados e intrusivos; interrupciones de la audiencia en sus flujos de contenido con los medios, derivadas de los cambios en las formas de consumo; el empoderamiento del trabajo de la audiencia y la política micro-macro de la acción de la misma. Para Das (2017), el período 2004-2014 se erige como una década transformativa, que ha llevado al análisis de audiencia a cotas desconocidas, pero muy significativas para los estudios de comunicación.

\section{DESAFÍOS METODOLÓGICOS PARA EL ESTUDIO DE AUDIENCIAS ACTIVAS}

Los estudios comunicativos de la recepción han pasado del enfoque conductista a los estudios culturales, y de ellos a la participación, entendida como evolución del culturalismo provocada por la actual situación de hiperconectividad causada por la tecnología. Se produce una orientación a los aspectos públicos, tras una prolongada preocupación académica por el dominio privado de la esfera familiar. No obstante, los distintos paradigmas en el seno de la investigación sobre audiencias continúan teniendo utilidad, en tanto en cuanto estos paradigmas coexisten porque todos los roles de la audiencia asociados permanecen en la sociedad (Livingstone, 2013, p. 28).

La misión de la academia ahora es averiguar qué modos de participación están permitidos, en las distintas infraestructuras tecnológicas, para que los ciudadanos 
medien en las esferas sociales. Además, resulta de interés conocer cómo la población se compromete y negocia nuevas formas de conexión en torno a los medios (Livingstone, 2013, p. 28). Para alcanzar estos retos epistemológicos se necesita de interdisciplinariedad académica, ante la evidencia teórica -procedente de distintas áreas del conocimiento- de que es "impracticable comprender a la audiencia por indicadores de consumo y efectos directos" (Nightingale, 1999, pp. 20-21).

El debate radica en hasta qué punto las teorías y métodos previos para investigar audiencias pueden ser útiles para los nuevos medios, o si bien se requiere de un replanteamiento significativo en esa materia (Livingstone, 2004). A pesar del abundante número de medios, autores como Webster y Ksiazek (2012) señalan que la intersección es habitual en los productos culturales, es decir, el contenido de los medios tiende a ser replicado entre plataformas (Boczkowski, 2010), por lo que la posibilidad de tener mucho en común culturalmente es frecuente.

La apreciación anterior tiene trascendencia metodológica y quiebra el mito de los enclaves, que sostenía que vivimos en microculturas de mercados altamente fragmentados con poco en común (Anderson, 2006). Sin embargo, esto no quiere decir que debamos estudiar individualmente los medios. Internet y fenómenos como el transmedia ${ }^{1}$, que desarrolla una historia en diferentes plataformas (Davis, 2013; Scolari, 2013), requieren de un análisis múltiple de medios. El transmedia emerge en base a una audiencia activa y participativa, con rasgos propios de una moderna cultura fan digital (Jenkins, 2010). Los sujetos ya no se relacionan con un solo medio, ni lo hacen de forma individualizada (Callejo Gallego, 2013), sino que muchas veces esa relación se produce en forma de comunidad conectada.

1 El transmedia se refiere al desarrollo de una misma historia en diferentes plataformas, cuyos componentes realizan una aportación distintiva al conjunto. El contenido del transmedia se extiende mediante una lógica multiplataforma, en la que cada parte funciona de manera autosuficiente. Es necesario diferenciar al verdadero transmedia del uso promocional de diversas técnicas, habitual en muchas empresas mediáticas (Davis, 2013, pp. 175-178).

RAEIC, Revista de la Asociación Española de Investigación de la Comunicación vol. 6, núm. 12 (2019), 123-146 
Existe una conexión entre las audiencias de tipo fan y el transmedia, ya que los fans se encuentran a la vanguardia de las audiencias contemporáneas (Davis, 2013). El transmedia tiene de original que aporta distintos productos para audiencias que comportan diferentes propensiones de compromiso (ibídem). La audiencia activa y participativa explora múltiples niveles de narrativa, creando y desarrollando contenido entre los receptores, y contribuyendo a su expansión (Green y Jenkins, 2011). Uno de los espacios televisivos para ello es el fenómeno Over the Top (OTT), que versa sobre la "distribución de contenidos de audio, vídeo y otros medios en la red abierta de Internet y por tanto fuera del control de los operadores de redes en la distribución de contenidos" (Prado, 2017, p. 127).

En este marco de audiencias más activas que nunca, cuyo grado de socialización las hacer ser catalogadas como "audiencias sociales" (Quintas Froufe y González Neira, 2015), la perspectiva cualitativa supone una vía privilegiada en aras de comprender el funcionamiento de la audiencia como agente activo (Callejo Gallego, 1995). Se mantienen, eso sí, problemas metodológicos asociados, como la preferencia por el método de la encuesta, que conlleva una serie de dificultades, como el cronocentrismo, la deseabilidad social o el privilegio de ciertas actividades sobre otras en las respuestas (Callejo Gallego, 2013).

Un reciente artículo de Schrøder (2019) analiza el proceso de reinvención de la investigación en recepción durante esta era digital, diferente al auge de la emisión televisiva de los años 80 , en la cual se enmarcó el máximo desarrollo de esta subdisciplina de los estudios de comunicación. Este investigador danés identifica tres grandes transformaciones, motivadas por la concentración teórica sobre los procesos de creación de sentidos (Schrøder, 2018, p. 155):

1. Cambio empírico que traslada el método desde el análisis de la decodificación de los receptores con el producto mediático al mapeo de la participación de la audiencia, efectuado sobre espacios más amplios como las redes sociales. 
2. Incorporación de contribuciones procedentes de las teorías de la participación y la mediatización. La academia respalda el uso de plataformas digitales para el compromiso cívico, pero es pesimista sobre el resultado de iniciativas participativas (Livingstone, 2013, p. 25).

3. Cambio metodológico, que deja atrás un diseño de la investigación puramente cualitativo para adoptar un método mixto.

Independientemente de la transcendencia transformadora de los estudios culturales, existe un interés académico por adaptar el modelo canónico de codificación/decodificación a las nuevas tecnologías y plataformas. Prueba de ello es el esfuerzo de varios investigadores (Shaw, 2017) por observar las prácticas digitales a través de las tres posiciones de lectura definidas por Hall: dominante, negociada y opuesta. Esta hibridación teórica permite abordar las implicaciones políticas de la interacción de la audiencia con las nuevas tecnologías. Se trata de una aproximación ideológica en una sociedad que huye de ellas, caracterizándose por formas líquidas de comportamiento (Bauman, 1999).

El auge del paradigma de la participación se encuentra motivado por un contexto digital de medios de comunicación que reformula las estructuras de acción de la población, que cada vez tiene más posibilidades de participación en una sociedad crecientemente mediatizada (Livingstone, 2013). Ya no podemos hablar de "masas" (Rasmussen, 2007); es la manera en que los mensajes son interpretados -siguiendo factores sociales y culturales- lo que permite entender ciertas actividades como masivas, dirigiéndose ahora el foco a interpretar el sujeto y el contexto del objeto mediático (Bolin, 2014, pp. 159-160). A pesar de estos cambios, las industrias de medios continúan mirando a los usuarios como masas, aunque de una forma más personalizada (Bolin, 2014, p. 169).

\section{CONCLUSIONES}

El modelo codificación/decodificación (Hall, 1980) sigue gozando de una potente capacidad explicativa. Más allá de su carácter pionero en integrar los estudios de 
audiencias en la crítica cultural, la focalización sobre los significados y el interés por analizar las fuerzas que interactúan en la producción (codificación) y recepción (decodificación) del mensaje constituyen una guía para la investigación semiótica del proceso comunicativo. Esta preocupación por los significados conecta con la dimensión ideológica, permitiendo conocer las implicaciones políticas de la comunicación, algo de interés dado su fuerte carácter partidista (Ang, 1995).

Frente a la estructura lineal o la preocupación excesiva por el intercambio de mensajes en el sistema de emisor-mensaje-receptor, el modelo de codificación/decodificación apuesta por interpretar el mensaje como único discurso con sentido, si bien utiliza el sistema anterior con fines descriptivos. El modelo de codificación/decodificación posee además lazos con los estudios de la desviación -incluso es considerado como un desarrollo de las subculturas de la desviación (Nightingale, 1999)-, ya que se preocupa por cómo los procesos de recepción afectan a las subculturas y dejan entrever formas de resistencia cultural. El debate sobre la hegemonía mediática sigue siendo recurrente en nuestros días, lo que pone en valor la propuesta de Hall.

Por otro lado, la literatura apunta al incremento de los procesos de participación en el marco de la proliferación de Internet, hablándose de un paradigma de la participación (Livingstone, 2013). La convergencia de plataformas digitales lleva a que algunos investigadores señalen que las audiencias están muertas, siendo ahora el tiempo de los usuarios (ibídem), pero este artículo ha referenciado evidencias empíricas de la vigencia de la estructura social en la recepción y, por tanto, del concepto de audiencias activas para entender la posible transformación de los consumidores en ciudadanos.

El panorama digital constituye un nuevo espacio sobre el que aplicar el modelo codificación/decodificación, partiendo de la interdisciplinariedad. El interés por la creación de sentidos permanece, desarrollado ahora en un paisaje mediático más amplio, que exige de métodos mixtos y de una decodificación más detallada, que mapee la participación de la audiencia (Schrøder, 2019). La interactividad de los cibermedios puede cruzarse con las fases de la recepción definidas por Hall-dominante, negociada 
y opuesta-, posibilitando la detección de las implicaciones políticas en los medios digitales (Shaw, 2017).

La investigación empírica debe centrarse en varios medios a la vez, entre los que se produce en ocasiones un solapamiento cultural (Callejo Gallego, 1995; Webster y Ksiazek, 2012), pero este posicionamiento resulta fundamental antes nuevas prácticas tan influyentes como el transmedia. Las comunidades son más dispersas que nunca, sin límites geográficos (Nightingale, 1999), entre las que se desarrollan estilos discursivos condicionados por la estructura social, así como por las circunstancias inmediatas de su interacción. En este punto es pertinente recordar la relevancia del concepto de formas de consumo, praxis mediática de la vida cotidiana y reflejo de la estructura social (Callejo Gallego, 1995).

En un contexto de innovaciones tecnológicas que ponen fin a las limitaciones asociadas a la participación (Bergillos García, 2016), el concepto de audiencia activa sirve como faro, con capacidad para orientar investigaciones sobre recepción para nuevos procesos comunicativos como el transmedia. Este tipo de aproximaciones científicas se siguen enfrentando a lugares comunes que dificultan la divulgación de sus estudios. La academia coincide en señalar la complejidad de los procesos comunicativos, lo que recalca la necesidad de estas investigaciones activas, que consiguen avanzar progresivamente en el conocimiento gracias a una descripción explicativa de la multiplicidad de factores que intervienen en los procesos de recepción.

\section{REFERENCIAS BIBLIOGRÁFICAS}

Adorno, T. W. y Horkheimer, M. (1974). La industria cultural. En D. Bell; D. MacDonald; E. Shils; M. Horkheimer; T. W. Adorno; P. F. Lazarsfeld y R. K. Merton (eds.), Industria cultural y sociedad de masas. Caracas: Monte Ávila.

Anderson, C. (2006). The long tail: Why the future of business is selling less of more. Nueva York: Hyperion. Recuperado de http://dl.motamem.org/long_tail_chris_anderson_motamem_org.pdf 
Ang, I. (1991). Desperately Seeking the Audience. Londres: Routledge.

Ang, I. (1995). Living Room Wars. Rethinking Media Audiences for a Postmodern World. Londres: Routledge.

Alonso Alonso, M. M. (2011). Televisión, audiencias y estudios culturales: reconceptualización de las audiencias mediáticas. Razón y palabra, 75, 1-25. Recuperado de

http://www.razonypalabra.org.mx/N/N75/monotematico 75/04_Alonso M75.pdf

Bauman, R. (1999). Modernidad líquida. Buenos Aires: Fondo de Cultura Económica.

Bergillos García, I. (2016). Participación de la audiencia y televisión en la era digital. Propuesta de análisis y evolución de las invitaciones a la participación en la TDT y en otras plataformas (Tesis doctoral). Universitat Autònoma de Barcelona, Barcelona. Recuperado de https://ddd.uab.cat/pub/tesis/2015/hdl_10803 308326/ibg1de.pdf

Bimber, B. (2014). Digital media in the Obama campaigns of 2008 and 2012: Adaptation to the personalized political communication environment. Journal of Information Technology \& Politics, 11(2), 130-150. https://doi.org/10.1080/19331681.2014.895691

Blumler, J. G. y Kavanagh, D. (1999). The Third Age of political communication: Influences and features. Political Communication, 16(3), 209-230. https://doi.org/10.1080/105846099198596

Boczkowski, P. J. (2010). News at work: Imitation in an age of information abundance. Chicago: University of Chicago Presss.

Bolin, G. (2014). The Death of the Mass Audience Reconsidered: From Mass Communication to Mass Personalisation. En S. Eichner y E. Prommer (eds.), Fernsehen: Europäische Perspectiven (pp. 159-172). Constanza y Münich: UVK. 
Bouza, F. (2002). Innovación tecnológica y cambio social. En X. Pérez Vilariño y X. M. Bouzada (coords.), Las encrucijadas del cambio social: homenaje al profesor José Luis Sequeiro Tizón (pp. 85-97). Vigo: Universidade de Vigo, Servizo de Publicacións.

Buckingham, D. (2013). Representing Audiences: Audience Research, Public Knowledge, and Policy. The Communication Review, 16, 51-60. https://doi.org/10.1080/10714421.2013.757487

Callejo Gallego, J. (1995). La audiencia activa. El consumo televisivo: discursos y estrategias. Madrid: CIS-Siglo XXI.

Callejo Gallego, J. (2013). Tiempo dedicado a los medios de comunicación por los jóvenes y los adolescentes: análisis de las diferencias. Communication \& Society, 26(2), $1-26$. Recuperado de http://dadun.unav.edu/bitstream/10171/35449/1/20130411123003.pdf

Das, R. (2017). Audiences: a decade of transformations - reflections from the CEDAR network on emerging directions in audience analysis. Media, Culture \& Society, 39(8), 1257-1267. https://doi.org/10.1177/0163443717717632

Davis, C. H. (2013). Audience Value and Transmedia Products. En T. Storsul y A. Krumsvik (eds.), Media Innovations (pp. 175-190). Gotemburgo: Nordicom.

Fiske, J. (1982). Introduction to Communication Studies. Londres: Methuen.

Fiske, J. (1987). Television Culture. Londres: Methuen.

Giddens, A. (1984). The Constitution of Society. Cambrige: Polity Press.

Gómez Mompart, J. L.; Gutiérrez Lozano, J. y Palau Sampio, D. (2015). La calidad periodística en España según la percepción de los periodistas. Estudios sobre el mensaje periodístico, 21 (1), 13-30. https://doi.org/10.5209/rev_ESMP.2015.v21.50647

Green, J. y Jenkins, H. (2011). Spreadable Media: How audiences create value and meaning in a networked economy. En V. Nightingale (ed.), The Handbook of Media 
Audiences (pp. 109-127). Malden: Wiley-Blackwell. https://doi.org/10.1002/9781444340525.ch5

Hall, S. (1980). Encoding/decoding. En S. Hall et al. (comps.), Culture, Media, Language. Londres: Hutchinson.

Hall, S. y Jefferson, T. (comps.) (1975). Resistance Through Rituals: youth subcultures in post-war Britain. Londres y Birmingham: Hutchinson y CCCS.

Hermes, J.; Van den Berg, A. y Mol, M. (2013). Sleeping with the enemy: Audience studies and critical literacy. International Journal of Cultural Studies, 16(5), 457-473. https://doi.org/10.1177/1367877912474547

Jenkins, H. (2010). Piratas de textos. Barcelona: Paidós.

Katz, E. y Lazarsfeld, P. F. (1955). Personal influence: The part played by people in the flow of mass communications. Glencoe: Free Press.

Lanham, R. (2006). The economics of attention: Style and substance in the age of information. Chicago: University of Chicago Press.

Lasswell, H. D. (1982). Estructura y función de la comunicación en la sociedad. En Moragas, M. (comp.), Sociología de la comunicación de masas. Barcelona: Gustavo Gili.

Lievrouw, L. A. y Livingstone, S. (2006). Introduction to the updated student edition. En L. A. Lievrouw y S. Livingstone (eds.), Handbook of new media: Social shaping and social consequences of ICTS (pp. 1-14). Londres: Sage. https://doi.org/10.4135/9781848608245.n1

Livingstone, S. (2004). The Challenge of Changing Audiences. Or, What is the Audience Researcher to do in the Age of the Internet? European Journal of Communication, 19(1), 75-86. https://doi.org/10.1177/0267323104040695

Livingstone, S. (2013). The Participation Paradigm in Audience Research. The Communication Review, 16, 21-30. https://doi.org/10.1080/10714421.2013.757174 
McCombs, M. (2012). Civic Osmosis: The Social Impact of Media. Communication \&

$\begin{array}{llll}\text { Society, } & \text { 25(1), } & \text { R-14. }\end{array}$

http://dadun.unav.edu/bitstream/10171/27355/1/McCOMBS.pdf

Merton, R. K. (1980). Ambivalencias sociológicas y otros ensayos. Madrid: Espasa Calpe.

Morley, D. (1980). The "Nationwide" Audience. Londres: British Film Institute.

Nightingale, V. (1999). El estudio de las audiencias. El impacto de lo real. Barcelona: Paidós.

Prado, E. (2017). El audiovisual online over the top: el futuro del audiovisual europeo y español. En E. Bustamante (coord.), Informe sobre el estado de la cultura en España 2017: igualdad y diversidad en la era digital (pp. 127-144). Madrid: Fundación Alternativas. Recuperado de http://interaccio.diba.cat/sites/interaccio.diba.cat/files/informe sobre el estado de la cultura 2017.pdf

Quintas Froufe, N. y González Neira, A. (coord.) (2015). La participación de la audiencia en la televisión: de la audiencia activa a la social. Madrid: AIMC. Recuperado de https://www.aimc.es/a1mc-

c0nt3nt/uploads/2017/05/2016 01participacion audiencia tv.pdf

Rasmussen, T. (2007). Nettverksintegrasjon og personlige medier. En M. Lüders; L. Pröitz у T. Rasmussen (eds.), Personlige medier: Livet mellom skjermene (pp. 247-269). Oslo: Gyldendal.

Schrøder, K. C. (2019). Audience Reception Research in a Post-broadcasting Digital Age. Television \& New Media, 20(2), 155-169. https://doi.org/10.1177/1527476418811114

Scolari, C. A. (2013). Narrativas transmedia. Cuando todos los medios cuentan. Barcelona: Deusto. 
Shannon, C. E. y Weaver, W. (1949). The Mathematical Theory of Communication. Chicago: University of Illinois Press.

Shaw, A. (2017). Encoding and decoding affordances: Stuart Hall and interactive media $\begin{array}{llll}\text { technologies. Media, } \quad \text { Culture } \quad \text { S Society, 39(4), } & \text { 592-602. }\end{array}$ https://doi.org/10.1177/0163443717692741

Sless, D. (1986). In Search of Semiotics. Londres: Croom Helm.

Sunstein, C. R. (2007). Republic.com 2.0. Princeton: Princeton University Press.

Webster, J. G. y Ksiazek, T. B. (2012). The Dynamics of Audience Fragmentation: Public Attention in an Age of Digital Media. Journal of Communication, 62, 39-56. https://doi.org/10.1111/j.1460-2466.2011.01616.x

Williams, R. (1981). Culture. Glasgow: Fontana. 